\title{
Innate immunity and alcoholic liver fibrosis
}

\author{
Won-IL Jeong and Bin Gao \\ Section on Liver Biology, Laboratory of Physiologic Studies, National Institute on Alcohol Abuse and \\ Alcoholism, National Institutes of Health, Bethesda, MD 20892
}

\begin{abstract}
The hepatic innate immune system consists of predominant innate immunity, which plays an important role in innate defense against infection and tumor transformation. Emerging evidence suggests that innate immunity also contributes to liver injury, repair, and fibrosis. This review summarizes the recent findings on the role of innate immunity in liver fibrosis. In general, Kupffer cells stimulate liver fibrosis via production of reactive oxygen species and proinflammatory cytokines, while NK cells inhibit liver fibrosis via directly killing of activated hepatic stellate cells and production of IFN- $\gamma$. Complement components, interferons, Toll-like receptors have also been shown to regulate liver fibrosis. Recent evidence also suggests that modulation of innate immunity by alcohol plays an important role in the pathogenesis of alcoholic liver fibrosis. These include alcohol amplification of the pro-fibrotic effects of Kupffer cells and suppression of the anti-fibrotic effects of NK/IFN- $\gamma$.
\end{abstract}

\section{Keywords}

Innate immunity; alcohol; liver fibrosis; natural killer cell; hepatic stellate cell

\section{Alcoholic Liver Fibrosis}

Chronic alcohol drinking is a leading cause of chronic liver disease worldwide. ${ }^{1}$ The typical spectrum of alcoholic liver disease includes fatty liver, alcoholic hepatitis, fibrosis, cirrhosis, and hepatocellular carcinoma. Interestingly, almost $100 \%$ heavy drinkers have fatty liver, but only $10-20 \%$ of them develop alcoholic hepatitis, fibrosis, and cirrhosis. Additionally, chronic alcohol consumption has been shown to accelerate liver injury in patients with viral hepatitis infection. ${ }^{2-4}$ For example, it was reported that there was a $34 \%$ increased rate of fibrosis in heavy drinkers who are infected with hepatitis $\mathrm{C}$ virus (HCV) compared with those who drank less. ${ }^{5}$ However, the molecular and cellular mechanisms underlying alcoholic liver fibrosis and alcohol acceleration of liver fibrosis are not completely understood. 6,7

Liver fibrosis is a common scarring response to virtually all types of chronic liver injury, including chronic alcoholic liver disease. The mechanisms for liver fibrosis have been dramatically elucidated in the last several decades but are still not fully understood. ${ }^{8-10}$ It is generally believed that after chronic liver injury, hepatocyte damage and Kupffer cell activation lead to hepatic stellate cell (HSC) activation. Activated HSCs produce a large amount of extracellular matrix (ECM) proteins, which accumulate within the subendothelial space of Disse and lead to liver fibrosis. Many other cell types may also be involved in production of extracellular matrix proteins and collagens, but likely play a less important role compared to HSCs. These include myofibrobalsts, bone marrow-derived progenitor cells, and hepatocytes.

Corresponding author: Bin Gao, M.D., Ph.D., Section on Liver Biology, NIAAA/NIH, 5625 Fishers Lane, Rm 2S-33, Bethesda, MD 20892. Tel: 301-443-3998; Fax: 301-480-0257; bgao@ mail.nih.gov. 
${ }^{8-10}$ Emerging evidence has suggested that HSC activation and proliferation are controlled by a variety of proinflammatory cytokines and reactive oxygen intermediates. Among them, TGF$\beta$ and PDGF are considered as the most potent stimulators for HSC transformation and proliferation, respectively. ${ }^{8-10}$ Recently, innate immunity has also been shown to play an important role in controlling the development and progression of liver fibrosis, which will be discussed below. In this review, we will also discuss the role of innate immunity in alcoholic liver fibrosis.

\section{Predominant Innate immunity in the liver}

The innate immunity system is responsible for the rapid, initial response of the organism to potentially dangerous stresses, including pathogens, tissue injury, and malignancy without specific recognition of foreign antigens. ${ }^{11}$ It includes physical barriers (eg. skin and mucous membranes), chemical barriers (eg. enzyme and acid secretions), humoral factors (eg. complement and interferons), phagocytic cells (eg. neutrophils and macrophages), and lymphocytic cells (eg. NK and NKT cells). Another important component of the innate immunity system is a group of recently identified pattern-recognition receptors that can specifically detect pathogens via recognizing specific structures called pathogen associated molecular patterns expressed by invading pathogens. ${ }^{11}$ These include complements, pentraxins, peptidoglycan-recognition proteins, lipid transferases, toll-like receptors (TLRs), NOD-like receptors (NLRs), RIG-like helicases etc. ${ }^{11}$

Interestingly, increasing evidence has suggested that the immune system in the liver consists of predominantly innate immunity. ${ }^{12}$ First, the liver is responsible for the biosynthesis of 80 $90 \%$ innate proteins including complements, secreted pattern recognition receptors and acute phase proteins; Second, the liver contains a large number of sinusoidal endothelial cells and Kupffer cells, which are responsible for clearance of soluble macromolecules and insoluble waste in the body. Kupffer cells account for $80-90 \%$ of the total population of fixed tissue macrophages in the body. Third, liver lymphocytes are enriched in innate immune cells including NK and NKT cells. ${ }^{13},{ }^{14}$ For example, mouse liver lymphocytes contain $10 \%$ NK cells, while rat and human liver lymphocytes contain about $30 \%$ to $50 \%$ NK cells. ${ }^{13,}{ }^{14}$ NKT cells constitute up to $30 \%$ of the intrahepatic lymphocyte population in mice. ${ }^{15}$ Fourth, liver cells also express a variety of pattern recognition receptors including TLRs. ${ }^{16-18}$ Finally and interestingly, the adaptive immunity in the liver seems less active because the liver is a major site to induce T cell apoptosis. ${ }^{19,}{ }^{20}$ Studies from the last several decades indicate that the hepatic innate immunity plays a key role not only in innate defenses against pathogens and transformed cells but also in regulating liver injury, repair, and fibrosis. ${ }^{21}$

\section{Innate Immunity and liver fibrosis}

Emerging evidence indicates that liver fibrosis is controlled by a variety of components of the innate immunity system including humoral factors (eg. complement and IFNs), phagocytic cells (eg. neutrophils and macrophages), lymphocytic cells (eg. NK and NKT cells), and pattern recognition receptors including TLRs. (a) Among the humoral factors, complement 5 was shown to stimulate while both IFN- $\alpha / \beta$ and IFN- $\gamma$ inhibit liver fibrosis. (b) Among the phagocytic cells, macrophages have been shown to play an important role in stimulating liver fibrosis while other phagocytic cells such as neutrophils and mast cells seem to have less effect. (c) Among the lymphocytic cells, NK cells was shown to inhibit liver fibrosis via killing activated HSCs while the role of NKT cells in liver fibrosis remain unclear. (d) Finally, it was shown that several pattern recognition receptors including TLRs are also involved in the pathogenesis of liver fibrosis. 


\section{Complement}

The complement system consists of about 30 soluble and membrane bound proteins that play a key role in the innate defense against microbe infection and in disposing immunologlobins and apoptotic cells. Recent studies indicate that the complement system is involved in the pathogenesis of a variety of liver disorders including liver fibrosis. ${ }^{22}$ Through genetic mapping, Hillebrandt et al ${ }^{23}$ identified the $44.7 \mathrm{Mb}$ region on mouse chromosome 2 contained a gene that is responsible for the development of liver fibrosis and further studies showed this gene is the complement 5 (C5) gene. Several inbred mouse strains with C5-deficience were resistant to liver fibrosis while transgenic expression of $\mathrm{C} 5$ gene increased the susceptibility of these mice to liver fibrosis. ${ }^{23}$ Clinical data also indicate that human $\mathrm{C} 5$ gene variants are associated with liver fibrosis in patients with chronic $\mathrm{HCV}$ infection. ${ }^{23} \mathrm{In}$ addition, it was reported that other complement components such as $\mathrm{C} 3, \mathrm{C} 4$, and mannose binding lectin (MBL) correlate negatively with the Child-Pugh score in patients with liver cirrhosis. ${ }^{24,}{ }^{25}$ Collectively, these data suggest that $\mathrm{C} 5$ promotes while $\mathrm{C} 3, \mathrm{C} 4$ and MBL may inhibit liver fibrosis.

\section{IFNs}

Data from experimental studies in rodent models clearly show that both IFN- $\alpha / \beta$ and IFN- $\gamma$ negatively regulate liver fibrosis. It was reported that IFN- $\gamma$-deficient mice are more susceptible to liver fibrosis induced by administration of $\mathrm{CCl} 4$ or feeding with a DDC diet, ${ }^{26,}{ }^{27}$ while treatment of animals with IFN- $\alpha / \beta$ or IFN- $\gamma$ ameliorates liver fibrosis in a variety of models. 27-30 The anti-fibrotic effects of IFNs are likely mediated via induction of HSC cycle arrest and apoptosis, ${ }^{31,32}$ activation of NK cell cytotoxicity against HSCs, ${ }^{27}$ and inhibition of collagen synthesis. ${ }^{30}$

IFN- $\alpha$ in combination with ribavirin is currently the standard pharmacological treatment for $\mathrm{HCV}$ infection and is effective in about $60 \%$ patients with $\mathrm{HCV}$ infection. ${ }^{33},{ }^{34}$ Clinical data have shown that IFN- $\alpha$ therapy improves serum levels of fibrotic markers and liver histology in both virologic responder and nonresponder patients with chronic HCV infection, ${ }^{35-39}$ but such therapy is less effective in patients with advanced fibrosis and cirrhosis. ${ }^{40}$ In contrast to IFN- $\alpha$, the clinical trial findings on the antiviral and anti-fibrotic therapy of IFN- $\gamma$ in HCV patients has been controversial although IFN- $\gamma$ has been shown to effectively inhibit liver fibrosis in animal studies (see above) and inhibit HCV replication in vitro. Clinical trials with a small number of patients showed that IFN- $\gamma$ treatment ameliorates liver fibrosis in patients with HBV infection ${ }^{41}$ and $\mathrm{HCV}$ infection, ${ }^{42}$ but a recent large clinical trial showed no beneficial effect of IFN- $\gamma$ in patients with advanced liver disease. ${ }^{43}$ The difference between these studies may be due to the selection of different population of patients. It is plausible to speculate that IFN- $\gamma$ may be effective in treating early stages of liver fibrosis, but not the later stage of cirrhosis.

\section{Kupffer cells}

Kupffer cells are the liver resident macrophages, which play a key role in clearance of insoluble waste in the body. In addition, Kupffer cells also contribute significantly to the pathogenesis of liver injury, fibrosis, and regeneration. In general, it is believe that, after injury, Kupffer cells become activated and release a variety of proinflammatory cytokines and reactive oxygen intermediates, which then activate HSCs, leading to liver fibrosis. ${ }^{44-46}$ On other hand, Kupffer cells or macrophages also play an important role in the resolution of liver fibrosis via production of metalloproteinase- $13 .{ }^{45,} 47$

\section{NK cells}

Over last several decades, many studies have shown that hepatic NK cells play an important role in innate immune response against tumors and microbial pathogens including viruses, 
bacteria and parasites. NK cells can kill virus-infected cells and tumors via releasing granules containing granzyme and peforin, death ligand as TRAIL and a variety of proinflammatory cytokines such as IFN- $\gamma$ and TNF- $\alpha$ Increasing evidence suggests that NK cells may also be involved in the pathogenesis of liver injury, fibrosis, and regeneration. ${ }^{27,32,48-51}$ For example, we and others have recently shown that activation of NK cells inhibits liver fibrosis in vivo. $27,32,51$ Further studies suggest that the inhibitory effects of NK cells on liver fibrosis are mediated via multiple mechanisms (Fig. 1). First, NK cells can directly kill early activated HSCs in NKG2D-, TRAIL-, MHC class-I-molecules- and granzyme- dependent manners. Interestingly, NK cells do not kill quiescent or fully activated HSCs. This is because only early activated HSCs express increased levels of NKG2D activating ligand retinoic acid early inducible gene 1 (RAE-1) but decreased levels of NK cell inhibiting ligand (MHC-1); Second, NK cells can also ameliorate liver fibrosis via releasing IFN- $\gamma$, which subsequently induces HSC cell cycle arrest and apoptosis via a signal transducer and activator of transcription 1 (STAT1)-dependent mechanism. ${ }^{32}$ Moreover, we examined the molecular mechanism by which RAE-1 expression was upregulated in early activated HSCs. Our findings suggest that during the early stages of activation, HSCs loss retinol, which can be metabolized into retinal through alcohol dehydrogenases 1 (ADH1) and $\mathrm{ADH} 3$, and subsequently metabolized into retinoic acid through retinal dehydrogenases 1 (Radh1) and Raldh2. RA induces expression of RAE-1. ${ }^{52}$ Finally, clinical data show that NK cells from HCV patients were able to kill human HSCs and their activities correlated negatively with the grade of liver fibrosis in these patients 51,53 . Taken together, NK cells seem to have anti-fibrotic functions and activation of NK cells could be a novel strategy to treat liver fibrosis. ${ }^{54}$

\section{NKT cells}

NKT cells are a subset of lymphocytes express both NK and T cell makers and consist of many subtypes. NKT cells are activated very early in the course of an immune response and play a key role in the innate defense against infection and tumor transformation. Recent studies suggest that NKT cells also contribute to liver injury and regeneration. ${ }^{55-59}$ However, the role of NKT cells in liver fibrosis remains obscure although the anti-fibrogenic effects of NKT cells have been documented in other organs. ${ }^{60,61}$ Since NKT cells contain several subtypes and produce an array of profibrogenic cytokines (such as IL-4 and IL-13) and antifibrogenic cytokines (such as IFN- $\gamma$ ), they may have a dual role in regulating liver fibrosis. Further studies are required to identify the role of NKT cells in liver fibrosis.

\section{TLRs}

There are 13 different TLRs identified so far. Several of them have been implicated in regulating the development and progression of liver fibrosis. Activated human HSCs express TLR2 and TLR4, activation of which resulted in NF- $\mathrm{KB}$ and JNK activation, followed by upregulation of chemokines and adhesion, suggesting activation of TLR2 and TLR4 on HSCs may be involved in inflammatory response. ${ }^{62,63}$ Activation of TLR9 on HSCs by apoptotic hepatocyte DNA has also been implicated in induction of liver fibrosis. ${ }^{64}$ In contrast, activation of TLR3 by poly I:C inhibits liver fibrosis. ${ }^{27,} 32$ The antifibrotic effect of poly I:C is likely mediated via activation of NK cells and production of IFN- $\gamma$ because such effect was diminished in NK cell-depleted mice and IFN- $\gamma$ knock out mice. ${ }^{27,} 32$ Finally, several other TLRs have been implicated in the pathogenesis in human primary biliary cirrhosis. ${ }^{65-67}$

\section{Innate immunity and alcoholic liver fibrosis}

\section{Alcohol amplification of the pro-fibrogenic effect of Kupffer cells}

There is increasing evidence that chronic alcohol consumption leads to liver fibrosis via upregulation of the pro-fibrogenic effects of Kupffer cells (Figure 2). It is well established that chronic alcohol consumption increases gut endotoxin leakage in humans and rodents, leading 
to endotoxaemia, which likely contributes to the development of alcoholic hepatitis, fibrosis, and cirrhosis. ${ }^{68,69}$ LPS concentration was found at elevated levels in alcoholic patients and rodent models exposed ethanol. ${ }^{70,71}$ In addition, chronic alcohol consumption upregulates expression of CD14 on Kupffer cells, further increasing the sensitivity of Kupffer cells to LPS. ${ }^{72-74}$ Chronic alcohol consumption also enhances responsiveness of Kupffer cells to apoptotic cells, which results in production of more proinflammatory cytokines. ${ }^{75}$ Taken together, chronic ethanol consumption leads to elevation of hepatic LPS levels, which target CD14/ TLR4 receptors that are elevated after ethanol consumption, leading to production of proinflammatory cytokines such as TNF- $\alpha$, IL-6 and TGF- $\beta 1$, and subsequent activation of HSCs and liver fibrosis.

\section{Alcohol abrogation of the anti-fibrogenic effect of NK/IFN-Y}

Ethanol has been recognized for a long time as an immunosuppressant, including suppression of NK cell activity. ${ }^{76-79}$ Recent studies from our laboratory suggest that alcohol inhibition of NK/IFN- $\gamma$ could be an important mechanism contributing to alcohol-induced liver fibrosis and alcohol acceleration of liver fibrosis. We have integrated these finding in the Figure 3. First, chronic ethanol consumption decreases the number of NK cells in the liver and inhibits NK cell accumulation in the liver induced by poly I:C or IFNs. ${ }^{79},{ }^{80} \mathrm{We}$ have demonstrated that chronic ethanol consumption directly inhibits NK cell killing of activated HSCs via downregulation of NKG2D, TRAIL, granzyme, perforin and IFN- $\gamma$ expression on NK cells. 79,80 Second, alcohol consumption stimulates HSCs to produce TGF- $\beta$, which can inhibit the functions of NK cells. ${ }^{80}$ Third, alcohol abolishes the anti-fibrotic effect of poly I:C and IFN$\gamma$ via inhibiting its downstream signaling STAT1 activation. ${ }^{80}$ We have shown that poly I:C or IFN- $\gamma$ treatment activates hepatic STAT1 and inhibits liver fibrosis in control-fed mice, but not in ethanol-fed mice. In vitro treatment with IFN- $\gamma$ activates STAT1 in cultured HSCs, but such activation was suppressed in HSCs from ethanol-fed mice. Further studies suggest that ethanol inhibition of IFN- $\gamma$ activation of STAT1 is mediated via induction of SOCS1 expression and stimulation of hepatocytes to produce ROS, which subsequently inhibits IFN$\gamma /$ STAT1 signaling in HSC. ${ }^{80}$

\section{Modulation of other innate immunity components contributes to alcoholic liver fibrosis}

In addition to amplification of the profibrogenic effect of Kupffer cells and inhibition of the antifibrogenic effect of NK/IFN- $\gamma$ in the liver, alcohol modulation of other innate immunity components may also contribute to alcoholic liver fibrosis. For example, it was shown that chronic ethanol consumption induced accumulation of hepatic NKT cells and NKT cells contributed to alcoholic liver injury. ${ }^{81}$ It is plausible that modulation of NKT cells by alcohol may also contribute to alcoholic liver fibrosis. Several components of the complement system are involved in liver fibrosis 22,23 and alcoholic liver injury; 82,83 however, it is not clear whether modulation of the complement system by alcohol also contributes to alcoholic liver fibrosis or alcohol acceleration of liver fibrosis. Feeding mice with an alcohol containing diet for 2 weeks upregulated multiple TLRs in the liver and increased the sensitivity to liver inflammation induced by multiple bacterial products recognized by TLRs, ${ }^{18}$ suggesting that modulation of TLRs likely contributes to alcoholic liver fibrosis.

\section{In summary}

The hepatic immune system consists of predominant innate immunity, which plays an important role in regulating liver fibrosis. The role of Kupffer cells in liver fibrogenesis has been extensively investigated and the profibrogenic effects of Kupffer cells are well documented. In addition, Kupffer cells also contribute to the resolution of liver fibrosis. NK cells were recently identified to have anti-fibrogenic functions via directly killing of activated HSCs and production of IFN- $\gamma$. Complement 5 was shown to contribute liver fibrosis while 
the roles of other complement components in liver fibrosis remain obscure. TLR4 and TLR9 have been implicated in contributing to the pathogenesis of liver fibrosis but activation of TLR3 seems to inhibit liver fibrosis. Modulation of innate immunity by alcohol is an important mechanism contributing to alcoholic liver fibrosis and alcohol acceleration of liver fibrosis in patients with $\mathrm{HCV}$ infection. These include alcohol amplification of the profibrogenic effect of Kupffer cells and inhibition of the antifibrogenic effect of NK/IFN- $\gamma$ in the liver. Further understanding on the effects of innate immunity in alcoholic liver fibrosis and injury may help us identify novel therapeutic targets to treat alcoholic liver disease.

\section{Acknowledgments}

This work was supported by the intramural program of NIAAA, NIH. No conflicts of interest exist for all authors.

\section{References}

1. Williams R. Global challenges in liver disease. Hepatology 2006;44:521-6. [PubMed: 16941687]

2. Bhattacharya R, Shuhart MC. Hepatitis $\mathrm{C}$ and alcohol: interactions, outcomes, and implications. J Clin Gastroenterol 2003;36:242-52. [PubMed: 12590237]

3. Safdar K, Schiff ER. Alcohol and hepatitis C. Semin Liver Dis 2004;24:305-15. [PubMed: 15349807]

4. Peters MG, Terrault NA. Alcohol use and hepatitis C. Hepatology 2002;36:S220-5. [PubMed: 12407597]

5. Poynard T, Bedossa $P$, Opolon $P$. Natural history of liver fibrosis progression in patients with chronic hepatitis C. The OBSVIRC, METAVIR, CLINIVIR, and DOSVIRC groups. Lancet 1997;349:82532. [PubMed: 9121257]

6. Purohit V, Brenner DA. Mechanisms of alcohol-induced hepatic fibrosis: a summary of the Ron Thurman Symposium. Hepatology 2006;43:872-8. [PubMed: 16502397]

7. Siegmund SV, Dooley S, Brenner DA. Molecular mechanisms of alcohol-induced hepatic fibrosis. Dig Dis 2005;23:264-74. [PubMed: 16508291]

8. Friedman SL, Rockey DC, Bissell DM. Hepatic fibrosis 2006: report of the Third AASLD Single Topic Conference. Hepatology 2007;45:242-9. [PubMed: 17187439]

9. Iredale JP. Models of liver fibrosis: exploring the dynamic nature of inflammation and repair in a solid organ. J Clin Invest 2007;117:539-548. [PubMed: 17332881]

10. Bataller R, Brenner DA. Liver fibrosis. J Clin Invest 2005;115:209-18. [PubMed: 15690074]

11. Janeway CA Jr, Medzhitov R. Innate immune recognition. Annu Rev Immunol 2002;20:197-216. [PubMed: 11861602]

12. Gao BJW, Tian Z. Liver: an organ with predominant innate immunity. Hepatology. 2007in press

13. Racanelli V, Rehermann B. The liver as an immunological organ. Hepatology 2006;43:S54-62. [PubMed: 16447271]

14. Doherty DG, O'Farrelly C. Innate and adaptive lymphoid cells in the human liver. Immunol Rev 2000;174:5-20. [PubMed: 10807503]

15. Exley MA, Koziel MJ. To be or not to be NKT: natural killer T cells in the liver. Hepatology 2004;40:1033-40. [PubMed: 15486982]

16. Schwabe RF, Seki E, Brenner DA. Toll-like receptor signaling in the liver. Gastroenterology 2006;130:1886-900. [PubMed: 16697751]

17. Szabo G, Dolganiuc A, Mandrekar P. Pattern recognition receptors: a contemporary view on liver diseases. Hepatology 2006;44:287-98. [PubMed: 16871558]

18. Gustot T, Lemmers A, Moreno C, et al. Differential liver sensitization to toll-like receptor pathways in mice with alcoholic fatty liver. Hepatology 2006;43:989-1000. [PubMed: 16628628]

19. Crispe IN, Giannandrea M, Klein I, et al. Cellular and molecular mechanisms of liver tolerance. Immunol Rev 2006;213:101-18. [PubMed: 16972899]

20. Bertolino P, McCaughan GW, Bowen DG. Role of primary intrahepatic T-cell activation in the 'liver tolerance effect'. Immunol Cell Biol 2002;80:84-92. [PubMed: 11869365] 
21. Dong ZJ, Wei HM, Sun R, et al. The roles of innate immune cells in liver injury and regeneration. Cell Mol Immunol 2007;4:241-52. [PubMed: 17764614]

22. Qin XB, Gao B. The complement system in liver diseases. Cell Mol Immunol 2006;3:333-40. [PubMed: 17092430]

23. Hillebrandt $S$, Wasmuth HE, Weiskirchen R, et al. Complement factor 5 is a quantitative trait gene that modifies liver fibrogenesis in mice and humans. Nat Genet 2005;37:835-43. [PubMed: 15995705]

24. Baumann M, Witzke O, Canbay A, et al. Serum C3 complement concentrations correlate with liver function in patients with liver cirrhosis. Hepatogastroenterology 2004;51:1451-3. [PubMed: 15362774]

25. Chong WP, To YF, Ip WK, et al. Mannose-binding lectin in chronic hepatitis B virus infection. Hepatology 2005;42:1037-45. [PubMed: 16231358]

26. Shi Z, Wakil AE, Rockey DC. Strain-specific differences in mouse hepatic wound healing are mediated by divergent T helper cytokine responses. Proc Natl Acad Sci U S A 1997;94:10663-8. [PubMed: 9380692]

27. Radaeva S, Sun R, Jaruga B, et al. Natural killer cells ameliorate liver fibrosis by killing activated stellate cells in NKG2D-dependent and tumor necrosis factor-related apoptosis-inducing liganddependent manners. Gastroenterology 2006;130:435-52. [PubMed: 16472598]

28. Baroni GS, D'Ambrosio L, Curto P, et al. Interferon gamma decreases hepatic stellate cell activation and extracellular matrix deposition in rat liver fibrosis. Hepatology 1996;23:1189-99. [PubMed: 8621153]

29. Rockey DC, Chung JJ. Interferon gamma inhibits lipocyte activation and extracellular matrix mRNA expression during experimental liver injury: implications for treatment of hepatic fibrosis. J Investig Med 1994;42:660-70.

30. Inagaki Y, Nemoto T, Kushida M, et al. Interferon alfa down-regulates collagen gene transcription and suppresses experimental hepatic fibrosis in mice. Hepatology 2003;38:890-9. [PubMed: 14512876]

31. Rockey DC, Maher JJ, Jarnagin WR, et al. Inhibition of rat hepatic lipocyte activation in culture by interferon-gamma. Hepatology 1992;16:776-84. [PubMed: 1505921]

32. Jeong WI, Park O, Radaeva S, et al. STAT1 inhibits liver fibrosis in mice by inhibiting stellate cell proliferation and stimulating NK cell cytotoxicity. Hepatology 2006;44:1441-51. [PubMed: 17133483]

33. Pawlotsky JM, Chevaliez S, McHutchison JG. The hepatitis C virus life cycle as a target for new antiviral therapies. Gastroenterology 2007;132:1979-98. [PubMed: 17484890]

34. Younossi Z, Kallman J, Kincaid J. The effects of HCV infection and management on health-related quality of life. Hepatology 2007;45:806-16. [PubMed: 17326207]

35. Poynard T, McHutchison J, Manns M, et al. Impact of pegylated interferon alfa- $2 \mathrm{~b}$ and ribavirin on liver fibrosis in patients with chronic hepatitis C. Gastroenterology 2002;122:1303-13. [PubMed: 11984517]

36. Hiramatsu N, Hayashi N, Kasahara A, et al. Improvement of liver fibrosis in chronic hepatitis C patients treated with natural interferon alpha. J Hepatol 1995;22:135-42. [PubMed: 7790701]

37. Carrion JA, Navasa M, Garcia-Retortillo M, et al. Efficacy of antiviral therapy on hepatitis C recurrence after liver transplantation: a randomized controlled study. Gastroenterology 2007;132:1746-56. [PubMed: 17484872]

38. Zeuzem S. Treatment of chronic hepatitis C virus infection in patients with cirrhosis. J Viral Hepat 2000;7:327-34. [PubMed: 10971820]

39. Camma C, Di Bona D, Schepis F, et al. Effect of peginterferon alfa-2a on liver histology in chronic hepatitis C: a meta-analysis of individual patient data. Hepatology 2004;39:333-42. [PubMed: 14767986]

40. Everson GT, Hoefs JC, Seeff LB, et al. Impact of disease severity on outcome of antiviral therapy for chronic hepatitis C: Lessons from the HALT-C trial. Hepatology 2006;44:1675-84. [PubMed: 17133499] 
41. Weng HL, Wang BE, Jia JD, et al. Effect of interferon-gamma on hepatic fibrosis in chronic hepatitis B virus infection: a randomized controlled study. Clin Gastroenterol Hepatol 2005;3:819-28. [PubMed: 16234012]

42. Muir AJ, Sylvestre PB, Rockey DC. Interferon gamma-1b for the treatment of fibrosis in chronic hepatitis C infection. J Viral Hepat 2006;13:322-8. [PubMed: 16637863]

43. Pockros PJ, Jeffers L, Afdhal N, et al. Final results of a double-blind, placebo-controlled trial of the antifibrotic efficacy of interferon-gammalb in chronic hepatitis $\mathrm{C}$ patients with advanced fibrosis or cirrhosis. Hepatology 2007;45:569-78. [PubMed: 17326152]

44. Rivera CA, Bradford BU, Hunt KJ, et al. Attenuation of $\mathrm{CCl}(4)$-induced hepatic fibrosis by $\mathrm{GdCl}(3)$ treatment or dietary glycine. Am J Physiol Gastrointest Liver Physiol 2001;281:G200-7. [PubMed: 11408273]

45. Duffield JS, Forbes SJ, Constandinou CM, et al. Selective depletion of macrophages reveals distinct, opposing roles during liver injury and repair. J Clin Invest 2005;115:56-65. [PubMed: 15630444]

46. Nieto N. Oxidative-stress and IL-6 mediate the fibrogenic effects of [corrected] Kupffer cells on stellate cells. Hepatology 2006;44:1487-501. [PubMed: 17133487]

47. Fallowfield JA, Mizuno M, Kendall TJ, et al. Scar-associated macrophages are a major source of hepatic matrix metalloproteinase-13 and facilitate the resolution of murine hepatic fibrosis. $\mathbf{J}$ Immunol 2007;178:5288-95. [PubMed: 17404313]

48. Chen Y, Wei H, Sun R, et al. Increased susceptibility to liver injury in hepatitis B virus transgenic mice involves NKG2D-ligand interaction and natural killer cells. Hepatology 2007;46:706-15. [PubMed: 17626270]

49. Hines IN, Kremer M, Isayama F, et al. Impaired liver regeneration and increased oval cell numbers following T cell-mediated hepatitis. Hepatology 2007;46:229-41. [PubMed: 17596893]

50. Sun R, Gao B. Negative regulation of liver regeneration by innate immunity (natural killer cells/ interferon-gamma). Gastroenterology 2004;127:1525-39. [PubMed: 15521020]

51. Melhem A, Muhanna N, Bishara A, et al. Anti-fibrotic activity of NK cells in experimental liver injury through killing of activated HSC. J Hepatol 2006;45:60-71. [PubMed: 16515819]

52. Radaeva SWL, Radaev S, Jeong WI, Park O, Gao B. Retinoic acid signaling sensitizes hepatic stellate cells to NK cell killing via upregulation of NK cell activating ligand RAE1. Am J Physiol Gastrointest Liver Physiol. 2007 Aug 2; [Epub ahead of print]

53. Morishima C, Paschal DM, Wang CC, et al. Decreased NK cell frequency in chronic hepatitis C does not affect ex vivo cytolytic killing. Hepatology 2006;43:573-80. [PubMed: 16496327]

54. Gao BRS, Jeong W. Activation of natural killer cells inhibits liver fibrosis: a novel strategy to treat liver fibrosis. Expert Review of Gastroenterology and Hepatology. 2007[Epub ahead of print]

55. Takeda K, Hayakawa Y, Van Kaer L, et al. Critical contribution of liver natural killer T cells to a murine model of hepatitis. Proc Natl Acad Sci U S A 2000;97:5498-503. [PubMed: 10792025]

56. Dong Z, Zhang J, Sun R, et al. Impairment of liver regeneration correlates with activated hepatic NKT cells in HBV transgenic mice. Hepatology 2007;45:1400-12. [PubMed: 17523147]

57. Ito H, Ando K, Nakayama T, et al. Role of Valpha 14 NKT cells in the development of impaired liver regeneration in vivo. Hepatology 2003;38:1116-24. [PubMed: 14578850]

58. Nakashima H, Inui T, Habu Y, et al. Activation of mouse natural killer T cells accelerates liver regeneration after partial hepatectomy. Gastroenterology 2006;131:1573-83. [PubMed: 17064698]

59. Li B, Sun R, Wei H, et al. Interleukin-15 prevents concanavalin A-induced liver injury in mice via NKT cell-dependent mechanism. Hepatology 2006;43:1211-9. [PubMed: 16729307]

60. Kim JH, Kim HY, Kim S, et al. Natural killer T (NKT) cells attenuate bleomycin-induced pulmonary fibrosis by producing interferon-gamma. Am J Pathol 2005;167:1231-41. [PubMed: 16251408]

61. Kimura T, Ishii Y, Morishima Y, et al. Treatment with alpha-galactosylceramide attenuates the development of bleomycin-induced pulmonary fibrosis. J Immunol 2004;172:5782-9. [PubMed: 15100325]

62. Paik YH, Schwabe RF, Bataller R, et al. Toll-like receptor 4 mediates inflammatory signaling by bacterial lipopolysaccharide in human hepatic stellate cells. Hepatology 2003;37:1043-55. [PubMed: 12717385] 
63. Paik YH, Lee KS, Lee HJ, et al. Hepatic stellate cells primed with cytokines upregulate inflammation in response to peptidoglycan or lipoteichoic acid. Lab Invest 2006;86:676-86. [PubMed: 16619004]

64. Watanabe AHA, Gomes D, Town T, Badou A, Flavell R, Mehal W. Apoptotic hepatocyte DNA inhibits hepatic stellate cell chemotaxis via toll-like receptor 9. Hepatology. 2007 Aug 17; [Epub ahead of print]

65. Mao TK, Lian ZX, Selmi C, et al. Altered monocyte responses to defined TLR ligands in patients with primary biliary cirrhosis. Hepatology 2005;42:802-8. [PubMed: 16175622]

66. Kikuchi K, Lian ZX, Yang GX, et al. Bacterial CpG induces hyper-IgM production in CD27(+) memory B cells in primary biliary cirrhosis. Gastroenterology 2005;128:304-12. [PubMed: 15685542]

67. Moritoki Y, Lian ZX, Wulff H, et al. AMA production in primary biliary cirrhosis is promoted by the TLR9 ligand CpG and suppressed by potassium channel blockers. Hepatology 2007;45:314-22. [PubMed: 17256753]

68. Parlesak A, Schafer C, Schutz T, et al. Increased intestinal permeability to macromolecules and endotoxemia in patients with chronic alcohol abuse in different stages of alcohol-induced liver disease. J Hepatol 2000;32:742-7. [PubMed: 10845660]

69. Stern M, Carter EA, Walker WA. Food proteins and gut mucosal barrier. IV. Effects of acute and chronic ethanol administration on handling and uptake of bovine serum albumin by rat small intestine. Dig Dis Sci 1986;31:1242-8. [PubMed: 3769708]

70. Fukui H, Brauner B, Bode JC, et al. Plasma endotoxin concentrations in patients with alcoholic and non-alcoholic liver disease: reevaluation with an improved chromogenic assay. J Hepatol 1991;12:162-9. [PubMed: 2050995]

71. Nanji AA, Khettry U, Sadrzadeh SM, et al. Severity of liver injury in experimental alcoholic liver disease. Correlation with plasma endotoxin, prostaglandin E2, leukotriene B4, and thromboxane B2. Am J Pathol 1993;142:367-73. [PubMed: 8382006]

72. Enomoto N, Ikejima K, Yamashina S, et al. Kupffer cell sensitization by alcohol involves increased permeability to gut-derived endotoxin. Alcohol Clin Exp Res 2001;25:51S-4S. [PubMed: 11410742]

73. Enomoto N, Ikejima K, Bradford B, et al. Alcohol causes both tolerance and sensitization of rat Kupffer cells via mechanisms dependent on endotoxin. Gastroenterology 1998;115:443-51. [PubMed: 9679050]

74. Wheeler MD, Thurman RG. Up-regulation of CD14 in liver caused by acute ethanol involves oxidantdependent AP-1 pathway. J Biol Chem 2003;278:8435-41. [PubMed: 12482856]

75. McVicker BL, Tuma DJ, Kharbanda KK, et al. Effect of chronic ethanol administration on the in vitro production of proinflammatory cytokines by rat Kupffer cells in the presence of apoptotic cells. Alcohol Clin Exp Res 2007;31:122-9. [PubMed: 17207110]

76. Collier SD, Wu WJ, Pruett SB. Ethanol suppresses NK cell activation by polyinosinic-polycytidylic acid (poly I:C) in female B6C3F1 mice: role of endogenous corticosterone. Alcohol Clin Exp Res 2000;24:291-9. [PubMed: 10776665]

77. Boyadjieva N, Dokur M, Advis JP, et al. Chronic ethanol inhibits NK cell cytolytic activity: role of opioid peptide beta-endorphin. J Immunol 2001;167:5645-52. [PubMed: 11698436]

78. Boyadjieva NI, Chaturvedi K, Poplawski MM, et al. Opioid antagonist naltrexone disrupts feedback interaction between $\mathrm{mu}$ and delta opioid receptors in splenocytes to prevent alcohol inhibition of NK cell function. J Immunol 2004;173:42-9. [PubMed: 15210757]

79. Pan HN, Sun R, Jaruga B, et al. Chronic ethanol consumption inhibits hepatic natural killer cell activity and accelerates murine cytomegalovirus-induced hepatitis. Alcohol Clin Exp Res 2006;30:1615-23. [PubMed: 16930225]

80. Jeong WIPO, Gao B. Abrogation of the antifibrotic effects of NK cells/IFN-gamma contributes to alcohol acceleration of liver fibrosis. Gastroenterology. 2007in press

81. Minagawa M, Deng Q, Liu ZX, et al. Activated natural killer T cells induce liver injury by Fas and tumor necrosis factor-alpha during alcohol consumption. Gastroenterology 2004;126:1387-99. [PubMed: 15131799]

82. Pritchard MT, McMullen MR, Stavitsky AB, et al. Differential contributions of C3, C5, and decayaccelerating factor to ethanol-induced fatty liver in mice. Gastroenterology 2007;132:1117-26. [PubMed: 17383432] 
83. Bykov I, Junnikkala S, Pekna M, et al. Complement C3 contributes to ethanol-induced liver steatosis in mice. Ann Med 2006;38:280-6. [PubMed: 16754259]

84. Taimr P, Higuchi H, Kocova E, et al. Activated stellate cells express the TRAIL receptor-2/death receptor-5 and undergo TRAIL-mediated apoptosis. Hepatology 2003;37:87-95. [PubMed: 12500193] 


\section{NK cells}

Figure 1. Mechanism of NK cell killing of early activated hepatic stellate cells (HSCs)

Quiescent HSCs store 75\% of the body's supply of retinol (vitamin A). During the activation, retinol can be metabolized into retinal through alcohol dehydrogenases (ADHs), and subsequently metabolized into retinoic acid (RA) through retinal dehydrogenases (Radhs). RA induces expression of RAE-1. As an activating ligand for NK cells, RAE-1 initiates NK cell killing of activated HSCs through releasing TRAIL, which targets TRAIL receptors that are upregulated in activated $\mathrm{HSCs}^{84}$. In addition, expression of the NK cell inhibiting ligand MHC class I on activated HSCs is downregulated, resulting in diminishing the inhibitory signal from HSCs to NK cells and further activation of NK cells ${ }^{51}$. After activation, NK cells produce IFN- $\gamma$, which not only can amplify NK cell functions via upregulation of TRAIL and NKG2D expression but also can induce cell cycle arrest and apoptosis of HSCs in a STAT1-dependent manner ${ }^{32}$. (modified figure with permission from ${ }^{54}$ ). 
Extracellular matrix

(collagen fibers)

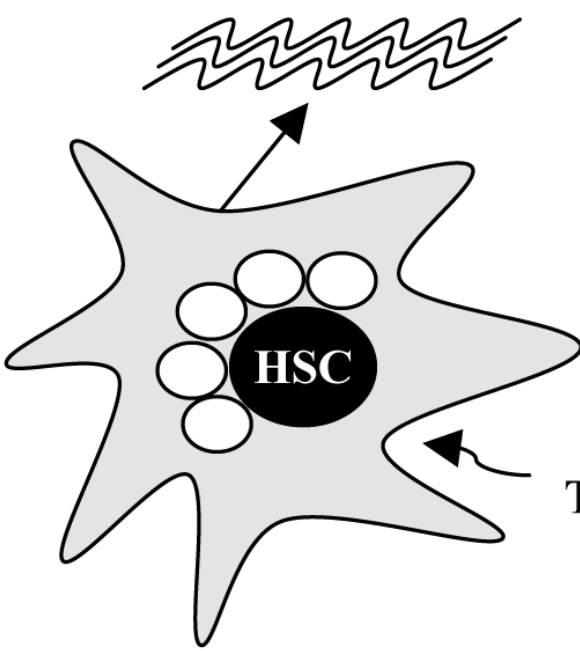

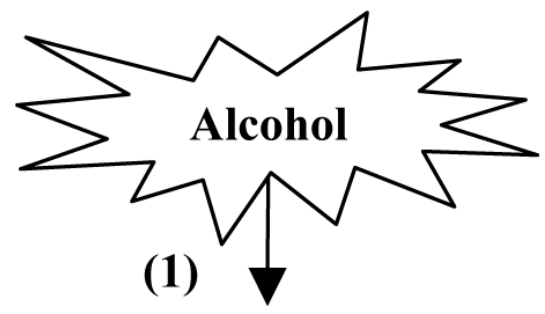

Endotoxin/LPS

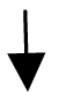

(2) 个CD14-TLR4

TNF- $\alpha$, IL-6, TGF- $\beta 1$, ROS

(3)

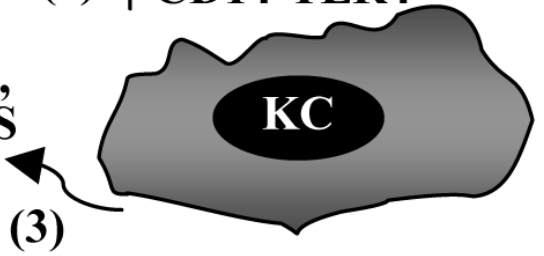

Figure 2. Alcohol amplifies the pro-fibrogenic effects of Kupffer cells

Alcohol consumption permeabilizes the gut, resulting in elevated hepatic endotoxin levels, which is followed by activation of Kupffer cells. Activated Kupffer cells produce a variety of proinflammatory cytokines and inflammatory mediators such as TNF- $\alpha$, IL-6, TGF- $\beta 1$ and reactive oxygen species (ROS), which then activate HSCs, leading to production of extracellular matrix (collagen fibers) and liver fibrosis. Chronic alcohol consumption also increases the sensitivity of Kupffer cells to endotoxin via upregulation of CD14 expression. 72-74 


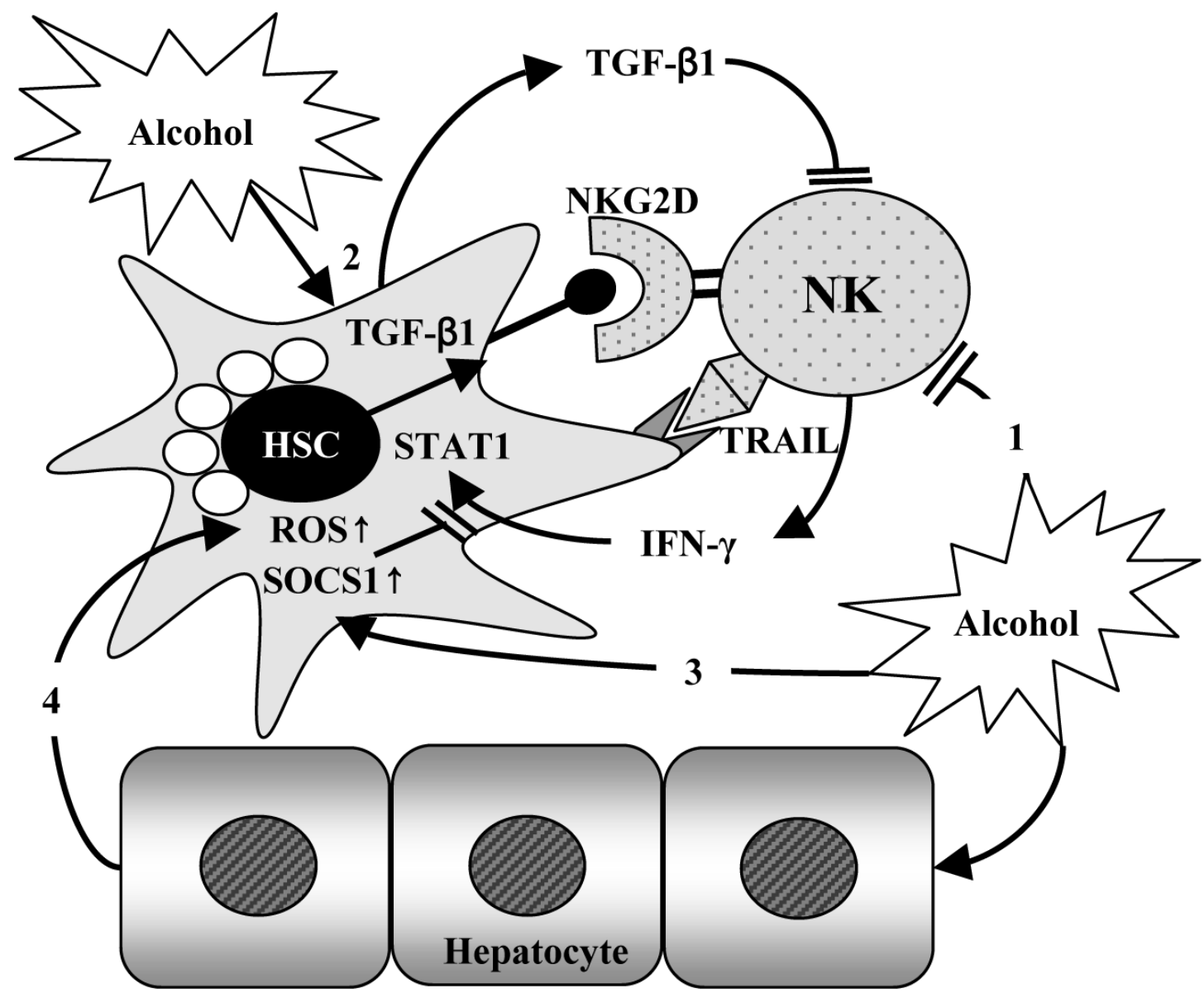

Figure 3. Alcohol inhibits the anti-fibrogenic effects of NK/IFN- $\gamma$

Alcohol inhibits the anti-fibrogenic effects of NK cells via multiple mechanisms including (1) alcohol decreases the number of NK cells and NK cell cytotoxicity against HSCs; (2) alcohol stimulates HSCs to produce TGF- $\beta 1$, followed by inhibiting NK cell killing of HSCs; (3) alcohol induces expression of suppressor of cytokine signaling 1 (SOCS1) protein on HSCs, followed by inhibiting IFN- $\gamma$ signaling in HSCs; (4) ethanol stimulates hepatocytes to produce oxidative stress, which then inhibits IFN- $\gamma$ signaling in HSCs. (modified figure with permission from ${ }^{80}$ ). 